\title{
Crucial role of primary healthcare professionals in the assessment and diagnosis of dementia
}

\author{
Hao Xue, PhD, Jingchun Nie, PhD, Yaojiang Shi *, PhD, \\ Center for Experimental Economics in Education, Shaanxi Normal University, PR China
}

Hong Kong Med J 2019;25:427-8

*Corresponding author: shiyaojiang7@gmail.com

https://doi.org/10.12809/hkmj195091

Worldwide, dementia is one of the major causes of disability and dependency among elderly populations. Globally, there are approximately 50 million people with dementia, and nearly 10 million new cases are diagnosed every year. ${ }^{1}$ The global costs and economic impacts of dementia to the society are huge-an amount equivalent to about 1 trillion dollars in 2019. ${ }^{2}$ China accounts for approximately $25 \%$ of the worldwide population of patients with dementia. $^{3}$ The overall prevalence of dementia in Chinese people aged $\geq 60$ years is $5.3 \%$ (95\% confidence interval $=4.3 \%-6.3 \%) .{ }^{4}$ Both the annual cost per person and the proportion of the national gross domestic product that dementia accounts for exceeds the global averages, imposing a substantial economic burden on China. ${ }^{5}$ In addition, other conditions that are common in elderly populations, such as frailty, hip fractures, and cancer $^{6-9}$ may further compound the consequences of dementia.

In this issue of the Hong Kong Medical Journal, Lam and colleagues report findings with important implications for the assessment and diagnosis of dementia. ${ }^{10}$ They review recent approaches for its diagnosis and highlighted their applications in primary healthcare settings. They summarise the importance and definition of dementia, categorise the differential diagnosis of cognitive impairment, and explain the diagnostic approach, including the history and physical examination, cognitive assessment, laboratory tests, and neuroimaging. Most importantly, Lam et al ${ }^{10}$ provide background information and advice for healthcare professionals on how they should utilise recent approaches in diagnosing dementia in clinical practice. Recent studies have used standardised patients who were recruited from local communities and extensively trained to present the same set of standard symptoms to multiple providers to assess quality of clinical care in China, India, and Kenya. They have shown that the quality of primary care in low-and-middle-income countries was poor. ${ }^{11-16}$ Most cases were incorrectly diagnosed based on a very lenient definition, and simple medical conditions were improperly managed in the majority of cases. Antibiotics were usually inappropriately overprescribed, and it was less likely for primary care providers to refer patients to higher-level hospitals for specialist care when needed. Although the large "know-do gap" - the gap between healthcare providers' knowledge and their performance in clinical practice-can explain part of the low quality, the lack of essential and updated knowledge to handle this medical condition is still one of the major reasons for substandard care. ${ }^{17-19}$ According to the National Institute for Health and Care Excellence guideline on dementia issued in 2018, primary care professionals are expanding their roles in the diagnosis and assessment of dementia, which highlights the need for updated education and training for healthcare professionals on dementia diagnosis and treatment. ${ }^{20}$

Lam et $\mathrm{al}^{10}$ provide background information for the diagnosis of dementia; however, there are caveats that require caution when we are using these methods. First, the costs of each type of diagnostic method should be considered. For example, neuroimaging can be very expensive and is not without hazard. It may not be suitable for extensive use in primary care. Second, the sensitivity and specificity of the tools should be explored to minimise misdiagnosis due to false positive or false negative results. Third, individuals with a high risk of cognitive impairment and dementia should also be identified. Patients with a profile of cardiovascular risk factors (ie, hypertension, diabetes, or dyslipidaemia) are more likely to have dementia. ${ }^{21}$ Diagnosis and screening may be more efficient if primary care professionals could recognise these patients earlier.

Not only should primary care providers be trained in management of dementia, but a national level project should be implemented to train specialists on dementia so as to enhance capacity to devise interventions in the community, such as establishment of more memory clinics. Training modules are suggested to be based on most recent research findings, including systematic reviews and meta-analysis. For instance, the 2018 National Institute on Aging-Alzheimer's Association Research Framework could be adopted in the design of training materials. ${ }^{22,23}$ Moreover, the prevalence of dementia and updated clinical management guidelines in China should be incorporated. Recent studies in Hong Kong have also highlighted some novel findings that could be applicable for care of dementia. ${ }^{24-28}$ In addition to training professionals, building an appropriately structured partnership, 
which takes incentives for both primary care providers and specialists, the welfare of patients and caregivers, and the cost of government and society into consideration, is also a challenge for policymakers in redesigning healthcare policy. It is also essential to enhance public awareness so that dementia patients and their caregivers are encouraged to seek help from professional care facilities for reducing their physical and mental burden. $^{5}$

\section{Author contributions}

All authors contributed to the concept or design, acquisition of data. analysis or interpretation of data, drafting of the article, and critical revision for important intellectual content. All authors had full access to the data, contributed to the study, approved the final version for publication, and take responsibility for its accuracy and integrity.

\section{Conflicts of interest}

The authors have declared no conflict of interest.

\section{Funding/support}

The authors are supported by the 111 Project (Grant No. B16031).

\section{References}

1. World Health Organization. Global Action Plan on the Public Health Response to Dementia, 2017-2025. Geneva: World Health Organization; 2017.

2. Wimo A, Guerchet M, Ali GC, et al. The worldwide costs of dementia 2015 and comparisons with 2010. Alzheimers Dement 2017;13:1-7.

3. GBD 2016 Dementia Collaborators. Global, regional, and national burden of Alzheimer's disease and other dementias, 1990-2016: a systematic analysis for the Global Burden of Disease Study 2016. Lancet Neurol 2019;18:88-106.

4. Wu YT, Ali GC, Guerchet M, et al. Prevalence of dementia in mainland China, Hong Kong and Taiwan: an updated systematic review and meta-analysis. Int J Epidemiol 2018;47:709-19.

5. Jia L, Quan M, Fu Y, et al. Dementia in China: epidemiology, clinical management, and research advances. Lancet Neurol 2019. pii: S1474-4422(19)30290-X.

6. Wong CW. Frailty assessment: clinical application in the hospital setting. Hong Kong Med J 2018;24:623-8.

7. Liu SK, Ho AW, Wong SH. Early surgery for Hong Kong Chinese elderly patients with hip fracture reduces short-term and long-term mortality. Hong Kong Med J 2017;23:374-80.

8. Leung KS, Yuen WF, Ngai WK, et al. How well are we managing fragility hip fractures? A narrative report on the review with the attempt to set up a Fragility Fracture Registry in Hong Kong. Hong Kong Med J 2017;23:264-71.

9. Lai CK, Igarashi A, Lau NM, Yu CT. Cancer screening for older people: to screen or not to screen. Hong Kong Med J 2017;23:503-16.

10. Lam K, Chan WS, Luk JK, Leung AY. Assessment and diagnosis of dementia: a review for primary healthcare professionals. Hong Kong Med J 2019;25:473-82.

11. Das J, Woskie L, Rajbhandari R, Abbasi K, Jha A. Rethinking assumptions about delivery of healthcare: implications for universal health coverage. BMJ 2018;361:k1716.

12. Sylvia S, Xue H, Zhou C, et al. Tuberculosis detection and the challenges of integrated care in rural China: A cross-sectional standardized patient study. PLoS Med 2017;14:e1002405.

13. Daniels B, Kwan A, Satyanarayana S, et al. Use of standardised patients to assess gender differences in quality of tuberculosis care in urban India: a two-city, cross-sectional study. Lancet Glob Health. 2019;7:e633-43.

14. Daniels B, Dolinger A, Bedoya G, et al. Use of standardised patients to assess quality of healthcare in Nairobi, Kenya: a pilot, cross-sectional study with international comparisons. BMJ Glob Health 2017;2:e000333.

15. Xue H, Hager J, An Q, et al. The quality of tuberculosis care in urban migrant clinics in China. Int J Environ Res Public Health 2018;15. pii:E2037.

16. Xue H, Shi Y, Huang L, et al. Diagnostic ability and inappropriate antibiotic prescriptions: a quasi-experimental study of primary care providers in rural China. J Antimicrob Chemother 2019;74:256-63.

17. Mohanan M, Vera-Hernández M, Das V, et al. The know-do gap in quality of health care for childhood diarrhea and pneumonia in rural India. JAMA Pediatr 2015;169:349-57.

18. Shi $\mathrm{Y}, \mathrm{Yi} \mathrm{H}$, Zhou $\mathrm{H}$, et al. The quality of primary care and correlates among grassroots providers in rural China: a crosssectional standardised patient study. Lancet 2017;390:S16.

19. Xue H, Shi Y, Medina A. Who are rural China's village clinicians? China Agric Econ Rev 2016;8:662-76.

20. Pink J, O’Brien J, Robinson L, Longson D; Guideline Committee. Dementia: assessment, management and support: summary of updated NICE guidance. BMJ 2018;361:k2438

21. Gottesman RF, Albert MS, Alonso A, et al. Associations between midlife vascular risk factors and 25-year incident dementia in the Atherosclerosis Risk in Communities (ARIC) Cohort. JAMA Neurol 2017;74:1246-54.

22. Wei J, Hu Y, Zhang L, et al. Hearing impairment, mild cognitive impairment, and dementia: A meta-analysis of cohort studies. Dement Geriatr Cogn Dis Extra 2017;7:44052.

23. Jack CR Jr, Bennett DA, Blennow K, et al. NIA-AA Research Framework: Toward a biological definition of Alzheimer's disease. Alzheimers Dement 2018;14:535-62.

24. Shea YF, Chu LW, Lee SC. A descriptive study of Lewy body dementia with functional imaging support in a Chinese population: a preliminary study. Hong Kong Med J 2017;23:222-30

25. Tse MM, Kwan RY, Lau JL. Ageing in individuals with intellectual disability: issues and concerns in Hong Kong. Hong Kong Med J 2018;24:68-72.

26. Yee A, Tsui NB, Chang YN, et al. Alzheimer's disease: insights for risk evaluation and prevention in the Chinese population and the need for a comprehensive programme in Hong Kong/ China. Hong Kong Med J 2018;24:492-500.

27. Shea YF, Chu LW, Lee SC, Chan AO. The first case series of Chinese patients in Hong Kong with familial Alzheimer's disease compared with those with biomarker-confirmed sporadic late-onset Alzheimer's disease. Hong Kong Med J 2017;23:579-85.

28. Luk JK, Chan FH, Hui E, Tse CY. The feeding paradox in advanced dementia: a local perspective. Hong Kong Med J 2017;23:306-10. 